\title{
Classical statistical methodology for accelerated testing of Solid Oxide Fuel Cells
}

\author{
Ploner, Alexandra; Hagen, Anke; Hauch, Anne
}

Published in:

Journal of Power Sources

Link to article, DOI:

10.1016/j.jpowsour.2018.05.034

Publication date:

2018

Document Version

Peer reviewed version

Link back to DTU Orbit

Citation (APA):

Ploner, A., Hagen, A., \& Hauch, A. (2018). Classical statistical methodology for accelerated testing of Solid Oxide Fuel Cells. Journal of Power Sources, 395, 379-385. https://doi.org/10.1016/j.jpowsour.2018.05.034

\section{General rights}

Copyright and moral rights for the publications made accessible in the public portal are retained by the authors and/or other copyright owners and it is a condition of accessing publications that users recognise and abide by the legal requirements associated with these rights.

- Users may download and print one copy of any publication from the public portal for the purpose of private study or research.

- You may not further distribute the material or use it for any profit-making activity or commercial gain

- You may freely distribute the URL identifying the publication in the public portal

If you believe that this document breaches copyright please contact us providing details, and we will remove access to the work immediately and investigate your claim 


\title{
Classical statistical methodology for accelerated testing of Solid
}

\section{Oxide Fuel Cells}

\author{
Alexandra Ploner ${ }^{*}$, Anke Hagen ${ }^{\mathrm{a}}$, Anne Hauch ${ }^{\mathrm{a}}$ \\ ${ }^{a}$ Technical University of Denmark, Department of Energy Conversion and Storage, Frederiksborgvej 399, \\ 4000 Roskilde, Denmark \\ [*]Corresponding author: aplo@dtu.dk, Phone:+4593511509
}

\section{Highlights}

- Semi-empirical model on SOFC degradation data for lifetime prediction

- Parameterization of SOFC degradation on extensive quantity of experimentally degradation data

- Detailed analysis of temperature and steam dependency for accelerated aging of Ni-YSZ electrodes

\section{Abstract}

Solid Oxide Fuel Cell (SOFC) lifetime prognosis is a substantial challenge for market introduction. This paper illustrates an accelerated testing approach based on an extensive quantity of experimental degradation data and suggests derivable degradation quantities for SOFC with focus on a large number of tests. The semi-empirical degradation models are based on the underlying physical degradation phenomena in the cell and are used for projection of temperature and steam impact on SOFC aging. Degradation tests performed at seven different temperatures and four different $\mathrm{p}\left(\mathrm{H}_{2} \mathrm{O}\right)$ in the fuel gas are used for evaluation. The key contribution of this study is parameterization of the aging model by experimental data while physical simulations in literature usually lack such robust empirical foundation.

\section{Keywords}

Solid Oxide Fuel Cell; accelerated testing; lifetime prediction; aging model 


\section{Introduction}

Solid Oxide Fuel Cells (SOFCs) are a promising technology for stationary and mobile power applications. Research activities over the last decades were dedicated to improve the performance and durability of the individual cell and stack components to reach commercial viability targets. For stationary applications (e.g. domestic combined heat and power generators) a lifetime of 40,000-80,000 h is expected to be competitive with current generalized generation or diesel generator technologies [1]. However, the estimation of lifetime and reliability of cells and stacks is a remaining critical issue for commercialisation. Long-term tests from $1 \mathrm{kh}$ up to $70 \mathrm{kh}$ are reported [2]. Yet, with enhancing durability of the SOFC technology, longer lifetime tests will be needed to identify failures and quantify long-term degradation rates. Logically, these tests are costly and often impractical. Hence, it will be desirable to determine SOFC lifetime by other means and in shorter times.

Accelerated test (AT) is a widely used approach in reliability engineering [3]. Within the reliability discipline, ATs are divided into two complementary but important approaches to derive reliability and lifetime information. For qualitative ATs ('torture testing') devices are subjected to a harsher-than-usual combination of operating parameters. This methodology is already implemented in SOFC long-term durability tests for example by performing redox-cycle tests and deliberate poisoning tests $[4,5]$. In general, this detrimental failure should be avoided under actual use. However, the experiments are necessary to assess and to contribute to improving e.g. electrode structure, composition or the stack design.

On the other hand, the quantitative $A T$ approach attempts to obtain degradation-time distribution at a specific level of operating conditions and utilize models to justified extrapolation to the nominal level. In many cases, the relationship between an accelerating variable (stressor) and the actual degradation mechanism based on physical/chemical theory can be extremely complex. Efforts within the physical/chemical interpretation approach are frequently based on a small number of experiments [6,7] and lack the measurement around the mean life. Thus, an empirically derived model building on statistical data 
may be an attractive alternative. This approach is routinely used in batteries [8,9] and microelectronics [10], but not yet in the field of SOFC/SOEC.

In analogy to lifetime tests of rechargeable batteries, SOFC lifetime tests can be separated into 'cycle life' and 'calendar life' tests. Aging of SOFCs leads to resistance changes due to e.g. mechanical and electrochemical aging processes. Mechanical failures occur for example due to mismatches of the temperature expansion coefficients of the different materials which the SOFC is composed of. Therefore, this failure is mainly introduced at start-up and shut-down procedures and dynamic operation of SOFC stacks and can be evaluated by simulating e.g. temperature cycles ('cycling life').

On the other hand, under constant operating conditions ('calendar life') primarily electrochemical aging takes place. It includes chemical and structural processes that all lead to an increase of the area specific resistance (ASR) over time, such as degradation of the fuel electrode (e.g. Ni-coarsening, Ni-Ni percolation loss, carbon and sulfur poisoning [11]), the oxygen electrode (e.g. Cr-poisoning [12], second phase formation [13]) and electrolyte (e.g. conductivity loss [13]). Aging phenomena for instance poisoning effects or secondary phase formation can be avoided to a certain extent via adjustments of fuel composition, choice of oxygen electrode or choice of operating conditions. On the other hand, microstructural degradation of the NiYSZ electrode and Cr-poisoning are critical processes, which are hardly preventable in state-of-the-art technology and therefore targeted aging phenomena.

This study focusses on classical accelerated 'calendar life' testing methods for SOFCs by semiempirical AT tests. The results are analysed with reliability methodology and experimentally derivable degradation quantifications for AT are proposed in the field of SOFC. 


\section{SOFC degradation analysis}

Degradation is fundamental to all devices. As the cell degrades, a decrease of performance follows. The progress of the performance degradation depends on time and stressor, i.e. one or more operating parameters. In Figure 1a a common SOFC voltage degradation [14] curve of a degradation test under constant operating conditions is shown, i.e. a so-called 'calendar life' test.
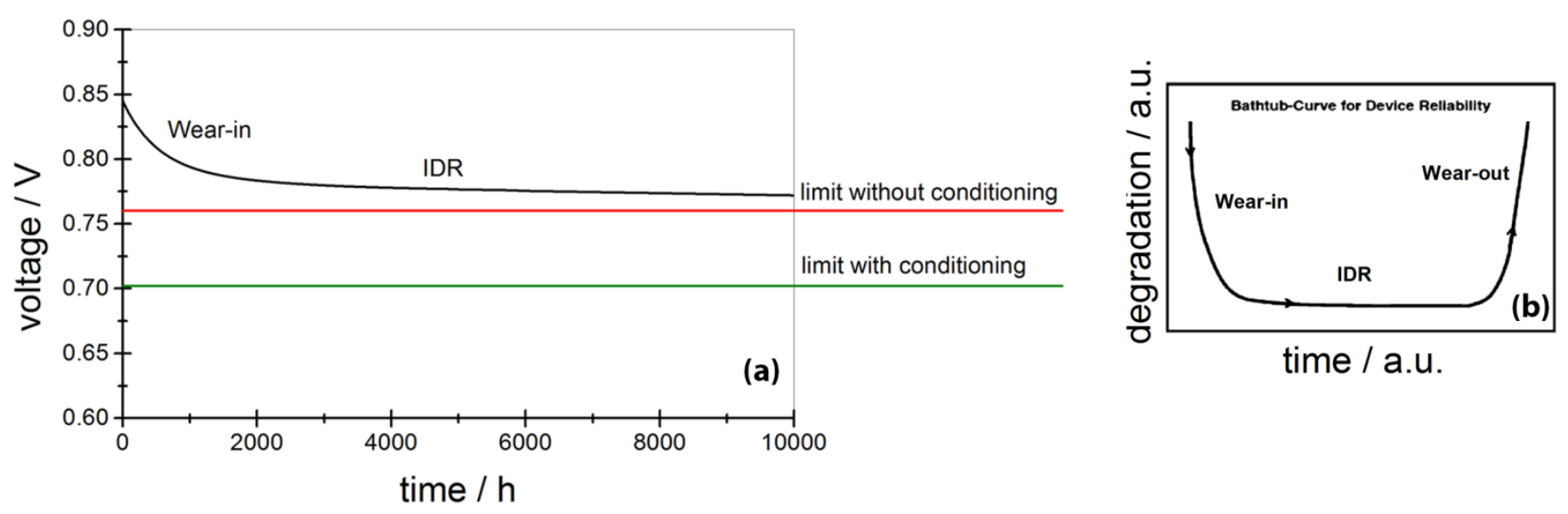

Figure 1 Voltage degradation curve for a long-term SOFC single cell test. End-of-life limits were calculated using a $10 \%$ voltages loss $\left(\Delta \mathrm{V} / \mathrm{V}_{\mathrm{o}}\right)$ based on the initial voltage with a wear-in period $\mathrm{V}_{0}(0 \mathrm{~h})=0.84 \mathrm{~V}$, red line and without a wear-in period $\mathrm{V}_{0}(2000 \mathrm{~h})=0.78 \mathrm{~V}$, green line (a). The bathtube curve is a modified illustration taken from [15], showing degradation over time (b).

Obviously, an initial degradation trend (wear-in) is followed by a relatively linear intrinsic degradation rate (IDR) and finally if the test is operated long enough a progressive degradation rate (= wearout) region might occur $[14,16]$. The degradation pattern over time follows therefore typically a bathtubshaped curve for device degradation [15]. Particularly, the wear-in (= initial degradation) causes challenges for lifetime prediction and complicates reporting of degradation rates for SOFC tests, because a simple extrapolation is not possible for short testing times. In fact, different lifetime limits are obtained whether or not a wear-in period is considered (see Figure 1a). By extrapolation of the IDR, the corresponding end-of-life 
equals to approx. $23,300 \mathrm{~h}$ vs. $87,900 \mathrm{~h}$ and demonstrates the impact of the wear-in region on lifetime prediction. In the field of reliability engineering such an effect is not unfamiliar and can be encountered if large differences of degradation rates of two different degradation populations exist for one device. Each population is a sum of various degradation phenomena. If the two degradation modes are clearly separated in time, it is possible to discriminate between the two processes. For SOFC lifetime it is crucial to eliminate the wear-in region, so that the end-of-life target of e.g. $10 \%$ voltage loss for SOFC as proposed by the U.S. Department of Energy [17] becomes a feasible objective. In SOFCs, this could be achieved by designing an adequate accelerated conditioning treatment which removes the initial degradation, i.e. the wear-in period.

As seen in previous work $[18,19]$ the degradation in the wear-in region is dominated by degradation processes due to the fuel electrode in state-of-the-art cells. Therefore, particularly stressors affecting fuel electrode degradation can be considered relevant to design an accelerated conditioning process. According to many experimental studies high steam/hydrogen ratio [20,21] in the fuel or high temperature [22,23] can be possible degradation 'controllers', as they tend to accelerate microstructural changes of the fuel electrode and thereby yielding faster performance stabilization. Furthermore, as SOFCs are mostly operated in galvano- or potentiostatic mode - current density or overpotential can be considered as additional stressors. However, so far current density/overpotential seem to have no effect on the microstructural degradation of the Ni-YSZ electrode [24] or only show a subordinate impact by regulation of the steam content in the fuel during operation of a SOFC [18]. In the following sections, the semi-empirical accelerating approach is outlined with focus on the temperature and steam partial pressure.

\subsection{Models for evaluation of degradation}

Different semi-empirical fitting models may be used for quantitative ATs. Most common are scaleacceleration models. These models presume that degradation $D$ at a particular stressor level $s$ is scaled by an accelerating factor $A F$

$$
D(s)=D\left(s_{o}\right) \cdot A F(s)
$$


Here $A F(s)$ is a positive function of $s$, fulfilling $A F\left(s_{0}\right)=1$. Furthermore, as $D$ will be represented as distribution of degradation data rather than a discrete value at a specific stressor level $s$ an appropriate distribution function (e.g. exponential, log-normal, Weibull) needs to be identified to describe $D$ with the mean value $\mu$ and the spread $\sigma$ of the distribution. This distribution is naturally caused by arbitrary random effects (e.g. different operators, differences in microstructure etc.)

With the focus on accelerating fuel electrode degradation, the major stressors temperature and steam content in the fuel are considered for determining the $A F$. First, the empirically derived Arrhenius type lifetime equation is used to take the accelerating impact of temperature into account [25]:

$$
[\mathrm{AF}(\mathrm{T})]=\exp \left[\frac{E_{A}}{\mathrm{k}_{\mathrm{B}}}\left(\frac{1}{\mathrm{~T}_{\mathrm{o}}}-\frac{1}{\mathrm{~T}_{\mathrm{S}}}\right)\right]
$$

where $E_{A}$ is the thermal degradation activation energy, $k_{B}$ the Boltzmann constant and $T$ the temperature at nominal conditions $T_{o}$ and at a specific stressor level $T_{s}$.

Based on sintering kinetics [26] and sintering studies of catalysts [27] the evaluation of the acceleration impact due to the steam partial pressure is considered via a power-law dependency.

$$
[\mathrm{AF}(\text { steam })]=\left(\frac{\mathrm{p}\left(\mathrm{H}_{2} \mathrm{O}\right)_{\mathrm{s}}}{\mathrm{p}\left(\mathrm{H}_{2} \mathrm{O}\right)_{0}}\right)^{\mathrm{n}}
$$

where $n$ is the acceleration exponent and $p\left(\mathrm{H}_{2} \mathrm{O}\right)_{o}$ and $p\left(\mathrm{H}_{2} \mathrm{O}\right)_{s}$ the steam partial pressure at nominal and stressor conditions, respectively.

\subsection{Quantification of degradation}

To obtain a lifetime prediction model from experimental aging tests, degradation metrics are necessary to derive at a mathematical description. In order to allow statistical treatment for degradation prognostics, the experiments should complementary favour fast and accessible 'aging quantities'. For Ni-YSZ electrodes separate metrics are considered to parameterize degradation based on experimental data. Their suitability in relation to testing a large number of samples is furthermore outlined.

Change of particle diameter of Ni-particles. 
Microstructural changes of the Ni-YSZ electrode often lead to electrochemical degradation of Ni-YSZ electrodes [29] and were shown to correlate with the ASR increase of the fuel electrode. In fact, the majority of Ni-YSZ microstructural changes can be obtained from ex-situ measurements in a furnace in which only gas composition, temperature and time are parameters to investigate microstructural changes and so would simplify the needed testing equipment.

Certainly, description/quantification of microstructural changes in a porous, complex structured material - as it is the case for Ni-YSZ electrodes - is generally difficult. However, in practice different parameters are used to quantify microstructural changes. Experimentally based durability studies are relying on such quantities to allow computation of lifetime and reliability. Most frequently, Ni-YSZ structures are geometrically parameterized via the mean particle diameter. The advantage of the mean particle diameter compared to other microstructural properties (i.e. triple phase boundary length, tortuosity factor) is that it is a rather easy accessible quantity and often derived from $2 D$ analysis. This is beneficial if investigating a large number of samples. Therefore, in the following the microstructural degradation parameter $\Delta r$ (the change of mean particle diameter) will be quantified as

$$
\Delta \mathrm{r}_{\text {microstruture }}=\frac{\text { particle diameter }_{\text {plateau }}-\text { particle diameter }_{\text {initial }}}{\text { particle diameter }_{\text {initial }}} \cdot 100
$$

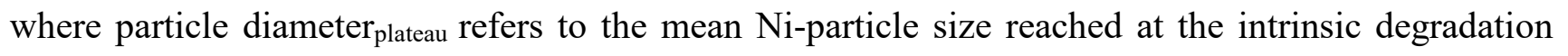
rate.

\section{Change of area specific resistance of Ni-YSZ electrodes.}

The performance and durability test results included in this work are obtained on SOFC cells applying electrochemical impedance (EI) measurements to quantify cell resistance. An adequate equivalent circuit model ideally allows separating between area specific resistance (ASR) degradation of fuel electrode, oxygen electrode and electrolyte. Hence, by modeling cell resistance data via cluster fitting impedance tools, analysis times can be drastically shortened and could allow for a standardized and automated result treatment for accelerated testing purposes. 
Recently, an analysis of a large number of ASR degradation data of Ni-YSZ electrodes obtained in cell durability tests over at least $1000 \mathrm{~h}$ was published [18]. Initial and final ASR values at standardized conditions were determined to allow comparison of differently operated cells. Therein, the degradation parameter $r$ (change of ASR) given in $\% \mathrm{kh}^{-1}$, was specified as

$$
\mathrm{r}_{\mathrm{ASR}}=\frac{\mathrm{ASR}_{\text {initial }}-\mathrm{ASR}_{\mathrm{final}}}{\mathrm{ASR}_{\text {initial }}} \cdot \frac{1000}{\mathrm{t}_{\text {testing }}} \cdot 100
$$

\section{Results and Discussion}

Using the above outlined degradation quantities, the following sections discuss the influence of two acceleration parameters 1) temperature and 2) steam content on the fuel electrode degradation to predict needed testing times concerning the wear-in region of calendar-life SOFC tests (see Figure 1). In section 3.1 and section 3.2 the influences of temperature directing Ni-particle coarsening (expressed via a microstructural degradation rate) will be analyzed. In section 3.3 the effect of steam content on the electrochemical degradation (expressed via ASR degradation rate) at nominal temperature condition will be evaluated furthermore.

\subsection{Acceleration parameter: Temperature influencing Ni-particle coarsening - study disregarding steam/hydrogen atmosphere}

The starting point for analyzing the effect of temperature with the statistical methodology involved selection of 34 long-term tests (in-house and results reported in literature) where measurements of the mean Ni-particle size were available.

The data had to fulfill the basic criterion of stabilization of Ni-YSZ degradation after few hundred hours operation as confirmed via EI spectroscopy or conductivity measurements or microstructural investigation with time where the particle diameter ${ }_{\text {plateau }}$ was expected to be reached. Table 1 lists the relevant test results 
and key test parameters all reported in literature or in-house data from Dept. of Energy Conversion and Storage, Technical University of Denmark.

Establishing a model based on literature and in-house results allowed focussing on the 'between-SOFC' variation when multiple SOFC-units from different manufacturers are tested and not only on 'within-SOFC' observations (same cell batch) thus including random effects naturally occurring due to the uncertainty of e.g. manufacturing processes.

The underlying uncertainties due to the difference in microscopic analysis method (analyzing and imaging method) are expected to be minimized via comparison of the relative change of one data point evaluated by the same technique. The difference of two individually applied analysis methods of four samples (two in-house samples and the two samples of Ref. [29]) could be assessed and varied from 1 to $8 \%$ which is still smaller than the total variation of the degradation data distribution (10-37\%). Furthermore, each mean value of the degradation data point resulted from a ratio of data analysed via the individual methods. Thus, the differences in analysis methods were additionally accounted for in the standard deviation of each temperature degradation point.

Table 1 References for the temperature influence study

\begin{tabular}{cccccccc} 
Ref. & $\begin{array}{c}\text { calendar-life } \\
\text { test }\end{array}$ & $\begin{array}{c}\text { analysis } \\
\text { method }\end{array}$ & $\begin{array}{c}\text { imaging } \\
\text { method }\end{array}$ & time / h & T / $\mathbf{C}$ & $\begin{array}{c}\mathbf{d} \text { (start) } / \\
\boldsymbol{\mu m}\end{array}$ & $\begin{array}{c}\mathbf{d} \text { (plateau) } / \\
\boldsymbol{\mu m}\end{array}$ \\
\hline in-house & electrochemical & 1 & 1 & 3500 & 700 & 1.18 & 1.21 \\
in-house & electrochemical & 1 & 1 & 1500 & 700 & 1.19 & 1.29 \\
Ananyev [23] & conductivity & 1 & 2 & 3000 & 700 & 1.48 & 1.68 \\
Marina [30] & electrochemical & $\mathrm{n} / \mathrm{s}$ & 4 & 2500 & 700 & 1.00 & 1.10 \\
in-house & electrochemical & 1 & 1 & 1500 & 700 & 1.10 & 1.18 \\
Ananyev [23] & conductivity & 1 & 2 & 3000 & 700 & 1.48 & 1.52 \\
in-house & electrochemical & 1 & 1 & 4000 & 700 & 1.18 & 1.25 \\
in-house & furnace & 2 & 3 & 775 & 750 & 0.70 & 0.74 \\
in-house & furnace & 2 & 3 & 775 & 750 & 0.68 & 0.72 \\
in-house & electrochemical & 1 & 1 & 3500 & 750 & 1.09 & 1.27 \\
in-house & electrochemical & 2 & 3 & 1500 & 750 & 0.80 & 1.00 \\
in-house & furnace & 2 & 3 & 775 & 750 & 1.06 & 1.14 \\
in-house & electrochemical & 2 & 3 & 9000 & 750 & 1.04 & 1.27 \\
in-house & furnace & 2 & 3 & 775 & 750 & 0.96 & 1.08 \\
Ananyev [23] & conductivity & 1 & 2 & 3000 & 800 & 1.48 & 1.78 \\
Faes [31] & electrochemical & 2 & 1 & 1900 & 800 & 0.78 & 0.90 \\
\hline
\end{tabular}




\begin{tabular}{cccccccc}
\hline Marina & electrochemical & $\mathrm{n} / \mathrm{s}$ & 4 & 2500 & 800 & 1.00 & 1.00 \\
Ananyev [23] & conductivity & 1 & 2 & 3000 & 800 & 1.48 & 1.88 \\
in-house & furnace & 1 & 1 & 1000 & 800 & 1.19 & 1.41 \\
in-house & furnace & 1 & 1 & 1000 & 800 & 1.19 & 1.40 \\
Parikh [32] & electrochemical & 3 & 5 & 2000 & 800 & 0.89 & 1.14 \\
in-house & electrochemical & 1 & 1 & 1500 & 800 & 1.10 & 1.24 \\
Faes [31] & electrochemical & 2 & 1 & 1130 & 800 & 0.63 & 0.85 \\
Tanasini [33] & electrochemical & 2 & 1 & 1000 & 850 & 0.64 & 0.77 \\
in-house [22] & electrochemical & 2 & 3 & 1500 & 850 & 0.80 & 1.02 \\
Marina [30] & electrochemcial & $\mathrm{n} / \mathrm{s}$ & 4 & 2500 & 900 & 1.00 & 1.30 \\
Parikh [32] & electrochemical & 3 & 5 & 2000 & 925 & 0.89 & 1.33 \\
Mantzouris [34] & conductivity & $\mathrm{n} / \mathrm{s}$ & $\mathrm{n} / \mathrm{s}$ & 1000 & 1000 & 1.56 & 3.11 \\
in-house [24] & conductivity & 1 & 1 & 300 & 1000 & 1.00 & 1.34 \\
Simwonis [35] & furnace & 2 & $\mathrm{n} / \mathrm{s}$ & 4000 & 1000 & 2.04 & 2.57 \\
in-house [24] & conductivity & 1 & 1 & 300 & 1000 & 1.00 & 1.24 \\
Jiang [36] & furnace & 2 & $\mathrm{n} / \mathrm{s}$ & 2000 & 1000 & 1.50 & 2.70 \\
Marina [30] & electrochemical & $\mathrm{n} / \mathrm{s}$ & 4 & 2500 & 1000 & 1.00 & 1.90 \\
in-house [24] & conductivity & 1 & 1 & 300 & 1000 & 1.00 & 1.37 \\
\hline
\end{tabular}

analysis method: $1 \mathrm{~d}_{50}$ of continuous phase size distribution, 2 mean length intercept method, 3 calculated from 3D, n/s not stated ; imaging method: 1 SEM-CC, 2 BSE/SE, 3 SE, 4 SEM/EDX, 5 FIB-SEM

The results were subjected to evaluation using a log-normal Arrhenius aging dependency, as described in Section 2.1. The log-normal probability plot analysis for $\mathrm{T}=700-850{ }^{\circ} \mathrm{C}$ and $1000{ }^{\circ} \mathrm{C}$ (only one measurement at 900 and $925^{\circ} \mathrm{C}$ did not allow analysis in that temperature range) is shown in Figure 2a and yielded a nearly constant shape parameter $\sigma$ (= standard log-normal distribution). The suggested log-normal distribution of degradation data was thus confirmed [3]. Furthermore, the assumed 1/T dependency was evaluated via an Arrhenius degradation plot (Fig. 2b) and subsequently the degradation activation parameter $E_{A}$ was calculated. 

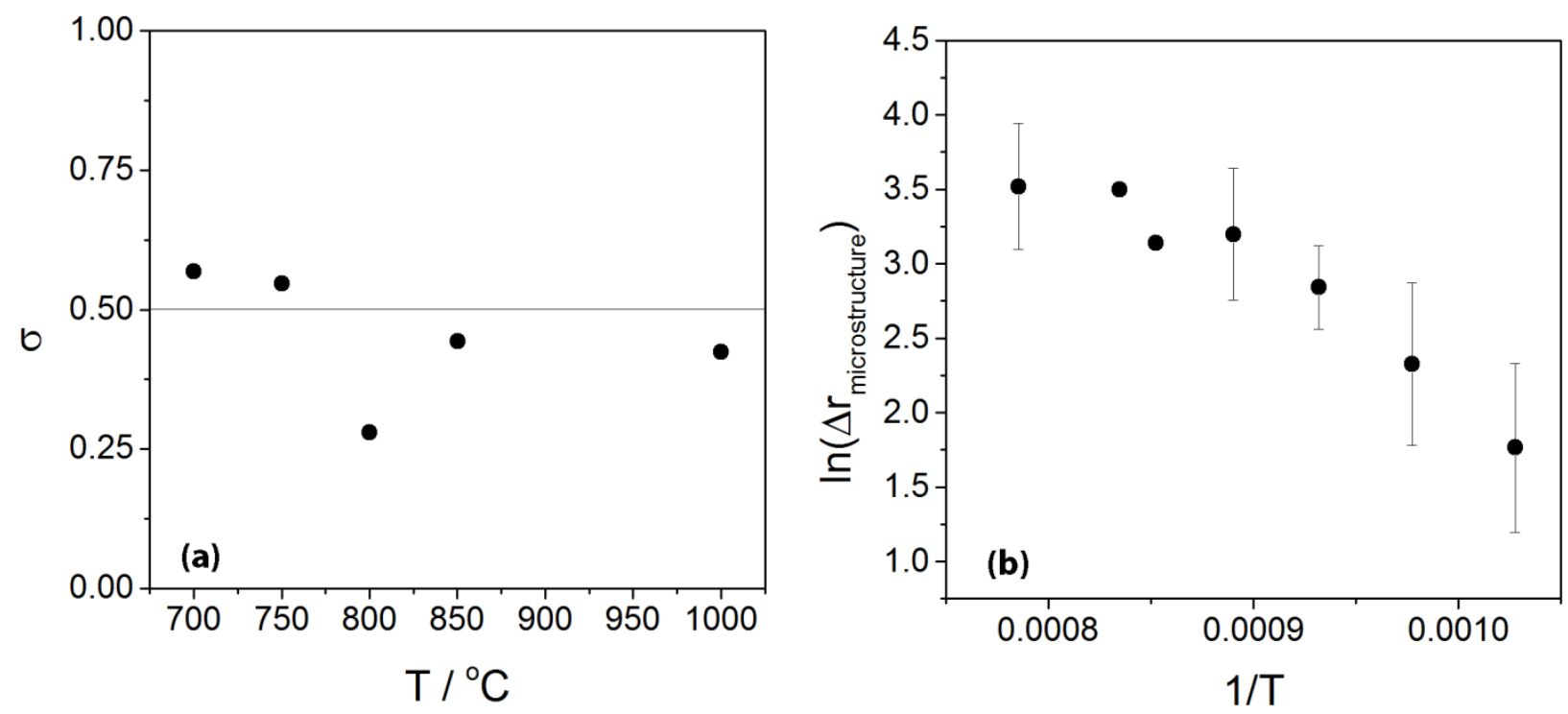

Figure 2 (a) Shape-parameter (distribution of degradation data) $\sigma$ vs. stressor T (b) Arrhenius degradation dependency of 34 long-term tested Ni-YSZ electrodes.

Concluding from the regression analysis, the model seems suitable to describe the impact of stressor $\mathrm{T}$ in the temperature range from $700-1000{ }^{\circ} \mathrm{C}\left(\mathrm{R}^{2}=0.882\right)$. However, the data shows tendencies to deviate from the Arrhenius behaviour, especially at $\mathrm{T} \geq 900{ }^{\circ} \mathrm{C}$. Removing of the data points $>900{ }^{\circ} \mathrm{C}$ significantly improved the regression $\mathrm{R}^{2}=0.994$. Several factors may explain this observed temperature limitation of NiYSZ degradation. To some extend this could be an effect of the quite general approach towards aging estimation based on literature data and own results (this will be further discussed in Section 3.2). On the other hand, this limit of acceleration could also be ascribed to a possible stabilization effect of the supporting YSZ matrix surrounding the Ni-particles. This stabilization may prevent Ni-particles to grow further, even at higher temperature. Thus, increasing the temperature beyond $850^{\circ} \mathrm{C}\left(900^{\circ} \mathrm{C}\right)$ does not lead to further accelerated growth of Ni-particles as the YSZ structure still remains immobile [37]. Nevertheless, so far a clear accelerated Arrhenius aging behavior is concluded from $700-850{ }^{\circ} \mathrm{C}$ by regression analysis and for this data-set $E_{A}$ was determined to be $\mathrm{E}_{\mathrm{A}, 700-850 \mathrm{C}}=88 \pm 4 \mathrm{~kJ} \mathrm{~mol}^{-1}$. It allows assessing the impact of the 
different $T$ stressor levels. Usually, three to four different temperature points in the AT matrix might be sufficient to parameterize an aging model for a specific cell type.

\subsection{Acceleration parameters: Temperature influencing Ni-particle coarsening - studies at high steam/hydrogen ratio and similar initial particle size}

To evaluate if the assumed acceleration dependency of temperature is also valid on an approach where steam atmosphere and initial particle size are considered as an individual influence, the following criteria were defined to evaluate particle coarsening only in high steam atmosphere and similar microstructures:

- The tested samples showed a porosity fraction of 22\%-31\%, a Ni-volume fraction between $30-33 \%$ and

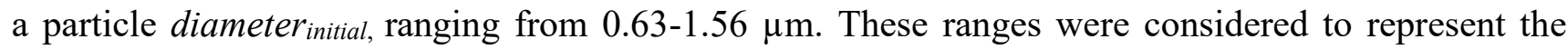
natural log-normal distribution of microstructural properties inside the sample, based on data from inhouse reference microstructures.

- The microstructural changes of the Ni-YSZ structure occurred in the presences of $\mathrm{p}\left(\mathrm{H}_{2} \mathrm{O}\right) \geq 0.2 \mathrm{~atm}$, either generated during operation or via sufficient external steam supply in an ex situ furnace test. This selection criterion was based on thermodynamic calculations for the stability of $\mathrm{Ni}(\mathrm{OH})_{2}$ species in a $\mathrm{H}_{2} / \mathrm{H}_{2} \mathrm{O}$ atmosphere [38]. This or similar Ni-hydroxide species are believed to favor a particular diffusion mechanism of Ni-particles.

These criteria led to exclusion of 13 data points from the original 34 . In the following, the same analysis as in section 3.1 was adopted to this data selection (labelled 'selected' in Figure 3) with again focusing on temperature dependency. Furthermore, the same analysis based on solely in-house results which show the most similar Ni-YSZ microstructure structure and where all cells were tested in high steam partial pressure (labelled 'in-house' in Figure 3). Therefore, the established T dependency seems capable to describe electrodes of a 'within-SOFC' population that are similarly produced and a 'between-SOFC' population where the initial microstructure is more variant. As a further consequence, initial particle size or the presence 
of steam seem to have secondary effect on the relative change of Ni-particle size specifically. It appears to be an effect dominated by temperature. This is in good agreement with former reported data on metal supported catalysts where particle sintering depends upon temperature, atmosphere, support and metal - with decreasing importance for the each variable and temperature being the most critical parameter [39].

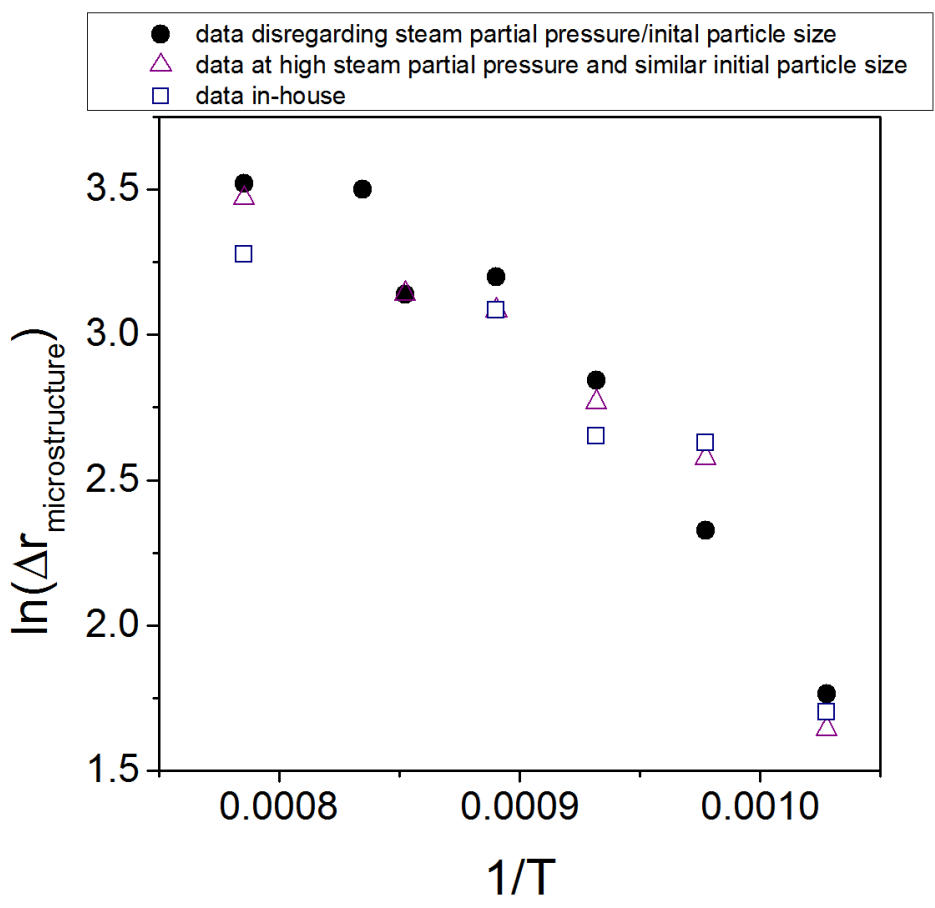

Figure 3 Arrhenius Ni coarsening dependency vs. reciproke stressor T with in-house ( $\square)$, selected $(\Delta)$ and included literature results $(\bullet)$

When comparing the accelerating impact of $\mathrm{T}$ on Ni-YSZ degradation with previous studies, only scarce data is available. Yet, the Arrhenius dependency was also used in a simulation study by Nakajo et al. [6]. An increase from $700-800{ }^{\circ} \mathrm{C}$ was estimated to accelerate coarsening of Ni-particles by approx. a factor of four at $\mathrm{p}\left(\mathrm{H}_{2} \mathrm{O}\right)=0.5$. The model herein predicts a more conservative acceleration by a factor 2.7 on the basis of a larger set of experimental data. 


\subsection{Acceleration parameter: Steam - studies at lower temperature}

In line with the particle size coarsening, a second set of data was evaluated. This data focus on variation of stressor steam at lower temperature. The relevant information on the data selection and testing information can be found in [18]. A short summary of important test specifications for the current study and results is given in Table 2 .

Table 2 ASR data from [18]

\begin{tabular}{|c|c|c|c|c|c|c|c|}
\hline Ref. & time / h & $\mathbf{T} /{ }^{\circ} \mathrm{C}$ & $\underset{\mathbf{A} \mathbf{c m}^{-2}}{\mathbf{j}}$ & $\mathrm{p}\left(\mathrm{H}_{2} \mathrm{O}\right)_{\text {in }}$ & $\begin{array}{c}\mathbf{A S R} R_{\text {initial }} / \\
\Omega \mathbf{c m}^{2}\end{array}$ & $\begin{array}{c}\mathbf{A S R} R_{\text {final }} / \\
\boldsymbol{\Omega}_{\mathbf{c m}^{2}} \\
\end{array}$ & $\mathbf{p}\left(\mathrm{H}_{2} \mathrm{O}\right)_{\text {out }}$ \\
\hline 4 & 2302 & 700 & 0.25 & 0.0 & 0.214 & 0.286 & 0.45 \\
\hline 51 & 1509 & 700 & 0.5 & 0.04 & 0.216 & 0.337 & 0.64 \\
\hline 10 & 2026 & 700 & 0.5 & 0.04 & 0.188 & 0.288 & 0.60 \\
\hline $17 *$ & 1512 & 700 & 0.75 & 0.05 & 0.217 & 0.343 & 0.63 \\
\hline 94 & 1513 & 750 & 0.75 & 0.15 & 0.180 & 0.294 & 0.68 \\
\hline 143 & 1243 & 750 & 0.75 & 0.15 & 0.160 & 0.228 & 0.70 \\
\hline 144 & 1565 & 750 & 0.75 & 0.16 & 0.173 & 0.242 & 0.66 \\
\hline 85 & 1575 & 750 & 0.25 & 0.16 & 0.184 & 0.293 & 0.69 \\
\hline $92 \mathrm{a}$ & 1506 & 750 & 0.75 & 0.16 & 0.179 & 0.286 & 0.73 \\
\hline 83 & 1508 & 750 & 0.25 & 0.16 & 0.147 & 0.218 & 0.44 \\
\hline 98 & 1503 & 750 & 1.19 & 0.24 & 0.182 & 0.316 & 0.69 \\
\hline 185 & 1000 & 750 & 0.5 & 0.25 & 0.124 & 0.198 & 0.53 \\
\hline 95 & 1502 & 750 & 0.75 & 0.26 & 0.205 & 0.393 & 0.68 \\
\hline 52 & 1500 & 700 & 0.5 & 0.4 & 0.229 & 0.432 & 0.50 \\
\hline $39 *$ & 1013 & 750 & 0.75 & 0.4 & 0.107 & 0.182 & 0.56 \\
\hline 50 & 1321 & 700 & 0.5 & 0.4 & 0.173 & 0.367 & 0.52 \\
\hline
\end{tabular}

In this study [18] the degradation effect of steam outlet flow as a key degradation parameter for Ni-YSZ electrodes was clearly established. One of the conclusions was that the impact of current density on degradation should rather be described in terms of the effect of the steam partial pressure. It was incorporated into the accelerating variable and as a consequence, the trend became more definite [18]. The alternative approach here considers the spread of degradation rates due to current density in the probability density function over the mean $\mu$ inlet partial pressure - analogous to the statistical evaluation of the T influence. Focusing on the inlet partial pressure allows determination of a steam related AF in case of in-situ but likewise for ex-situ performed tests. 
Aside from the inlet steam partial pressure, empirically derived accelerated testing models are often also considering the relative humidity as steam stressor variable. In the investigated case, however, similar results were obtained for the steam dependency, either expressed as relative humidity or absolute partial steam pressure. Due to a small improvement in the regression analysis the absolute partial pressure is used for the semi-empirical evaluation.

The degradation vs. stressor steam was thus analyzed. The mean degradation rate at each steam stressor measurement seemed to follow again a log-normal distribution (consistency of shape parameter $\sigma=$ standard lognormal distribution). Thereafter, the impact due to partial pressure (see Eq.(3)) was studied via a powerlaw dependency and the exponent $n$ in Eq.(3) was determined (Figure 4b).
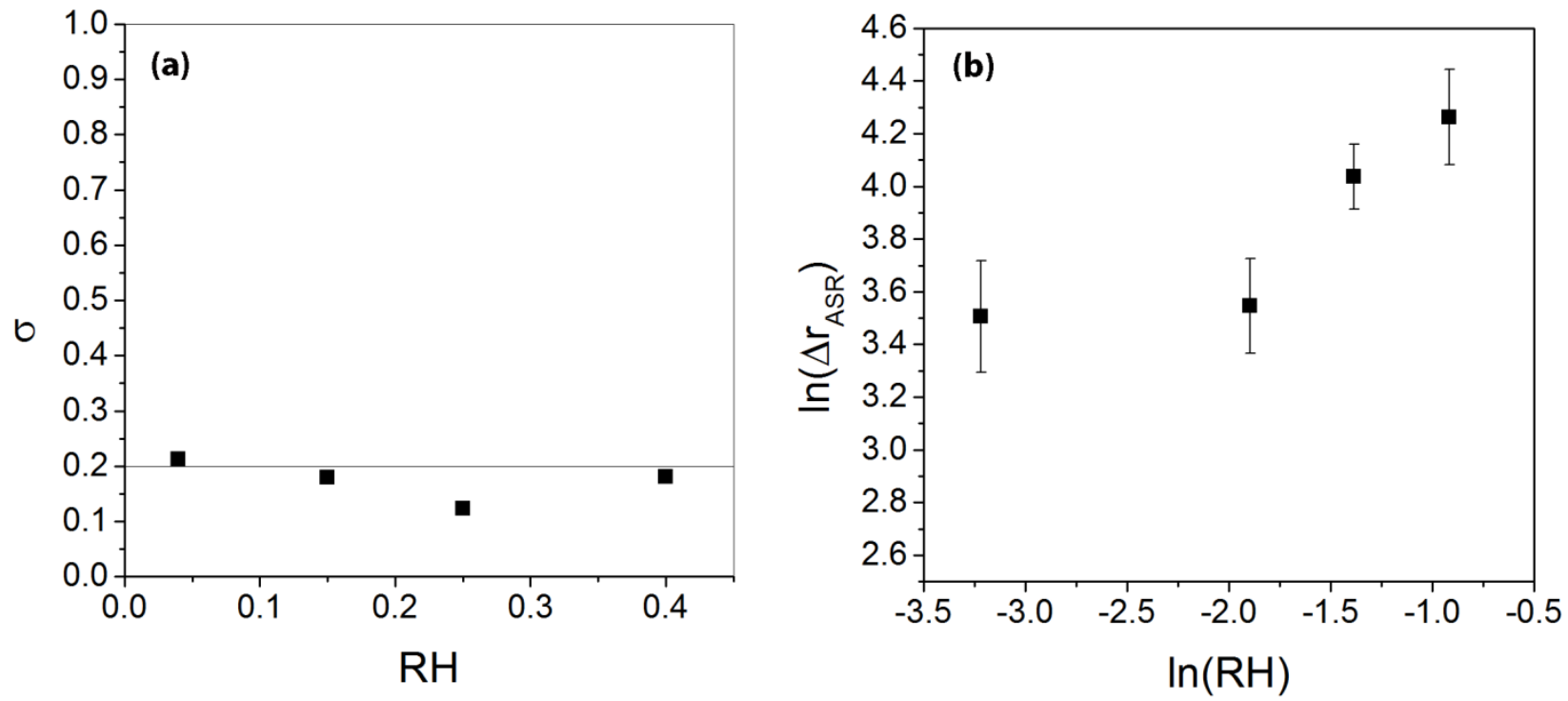

Figure 4 (a) Shape-parameter (distribution of degradation data) $\sigma$ vs. stressor steam given as relative humidity (RH) (b) Power-law plot of fuel electrode degradation.

Obviously, the power-law trend is not given over the complete stressor range (4-40\% RH). Yet, in Figure $4 b$ the degradation rate is seemingly lower for either $4 \%$ or $15 \%$ inlet steam partial pressure compared to $25 \%$ or $40 \%$. Thus, the tendency can be either seen for $15<25<40 \%$, however also for 
$4<25<40 \%$. Apparently there is a point of inflection occurring in the degradation data below $15 \%$ steam partial pressure which may indicate a change of degradation mechanism [15]. Therefore, the proposed semiempirical acceleration model can so far only be applied for tests with a steam partial pressure $>0.15 ;$ with the resulting power-law exponent of $n=0.72$.

\subsection{Combination of acceleration impact of stressors $T$ and $R H$}

Certainly, the ultimate aim for an accelerated conditioning process would be to combine the acceleration effect of the two stressors $T$ and steam partial pressure. The analysis of the two individual accelerating variables reveals firstly that temperature primarily determines the final Ni-particle diameter (with negligible influence of steam). Previous studies are certainly supporting this conclusion as they show similar dependencies of fuel electrode degradation upon the influence of temperature in different steam/hydrogen environments [20,40]. Secondly, the higher degradation at low temperature due to steam content may probably have a different degradation origin.

To combine the individual stressors for AT proposes, statistical evaluation of steam data at higher temperature is needed (e.g. $\left.850^{\circ} \mathrm{C}\right)$ to determine the interaction term. Additionally, a correlation function of the two degradation metrics would be needed as there might not be a linear connection between AF factors determined from microscopic and ASR based studies.

Despite these limits, the individual acceleration factors determined are still useful for manufacturers and for demonstrating the methodology to predict the acceleration impact. Figure 5 highlights the possibilities for valuable prediction of effects of accelerating factors for SOFC in this case for the experimental parameters included in this study. Similar statistical approaches could be applied to other key parameters for SOFC lifetime. Figure 5 clearly shows how the temperature is the dominating accelerating variable due to the exponential acceleration effect. Moreover, it needs to be noted that this model is limited to conditions supported by the experimental data. For example, it would not be correct to use the calculated 
activation parameter $\mathrm{E}_{\mathrm{A}}$ for predictions at lower $\mathrm{T}$. Even though operating SOFCs at $650{ }^{\circ} \mathrm{C}$ is certainly of technological relevance. The simulation of the acceleration factor is therefore limited to a specific data range.

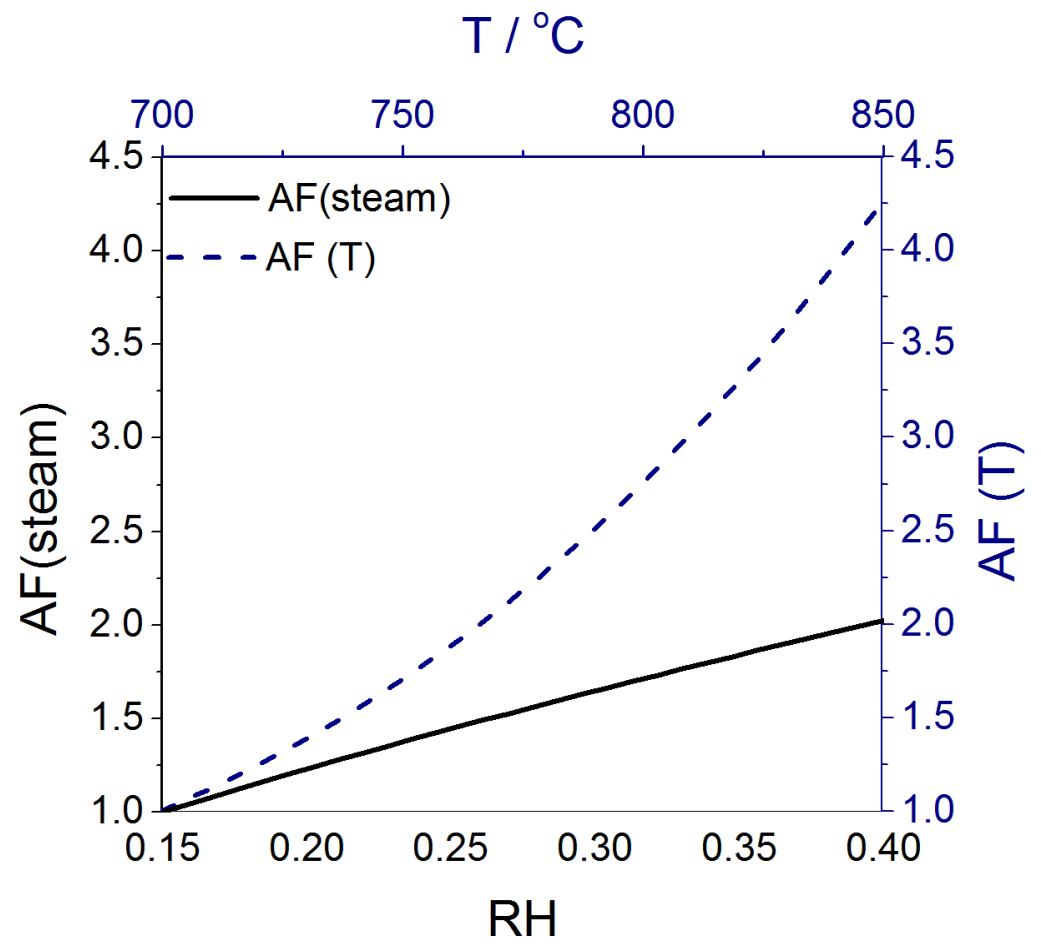

Figure 5 Comparision of the acceleration impact of the two individual stressors $\mathrm{T}$ and $\mathrm{RH}$ for nominal conditions $\left(\mathrm{s}_{0, \mathrm{~T}}=700{ }^{\circ} \mathrm{C}\right.$ and $\left.\mathrm{s}_{0, \mathrm{RH}}=0.15\right)$

\section{Conclusion}

In this work, a classical statistical approach to quantify SOFC degradation was proposed. An extensive data pool (34 microstructural and 16 electrochemical studies) of 'calendar life' aging tests of NiYSZ electrodes was statistically treated. Two different degradation parameters for the wear-in period were suggested (relative increase of Ni-particle size and increase of area-specific-resistance for Ni-YSZ electrodes) and in that way the accelerated aging impact of two stressors, temperature (T) and relative humidity (RH), was quantitatively analyzed. For the temperature dependency, a log-normal Arrhenius aging model was successfully applied. The model allows aging prediction in the temperature range between 700- 
$850^{\circ} \mathrm{C}$. Beyond these temperatures, the data could not be described via this model, indicating that there is a temperature limit for accelerating Ni-particle coarsening. For the electrochemically tested cells, the steam impact was evaluated and could be fitted via a power-law degradation model in a RH range from 15-40\%. At low RH (0-4\%) the data indicated that a different ageing mechanism was more significant.

For the case that the individual stressors accelerate different degradation phenomena of the Ni-YSZ structure, an acceleration model to combine the two stressors was proposed. This model needs to be validated in future work. The results of the statistical approach to SOFC degradation data and the here applied model based on empirical data is a powerful tool to optimize strategies for an accelerated conditioning procedure for SOFC.

\section{Acknowledgement}

The authors would like to thank colleagues at DTU Energy Conversion for technical assistance especially H. Henriksen and E.Abdellahi. Furthermore, funding by Energinet.dk (project 2014-1-12231 ForskEL 'SOFC4RET') and the European project EU-INSIGHT (grant agreement No. 735918) is gratefully acknowledged.

\section{Abbreviations}

ASR area specific resistance

AT Accelerated Test

EI electrochemical impedance

IDR intrinsic degradation rate

Ni-YSZ Nickel-Yttria Stablized Zirconia

RH relative humidity

SOFC Solid Oxide Fuel Cell 


\section{References}

[1] S. Mukerjee, R. Leah, M. Selby, G. Stevenson, N. Brandon Life and Reliability of Solid Oxide Fuel Cell-Based Products: A Review,in: N. Brandon, E. Ruiz-Trejo, P. Boldrin (Eds.) Solid Oxide Fuel Cell Lifetime and Reliability, Academic Press, 2017; pp 173-191.

[2] T. L. Skafte, J. Hjelm, P. Blennow, C. Graves, Proceedings of 12th European SOFC \& SOE Forum Chapter 6 (2016) 8-26.

[3] W. Nelson, Accelerated Life Testing: Statistical Models, Test Plans and Data Analysis, John Wiley \& Sons New York, 2004.

[4] S. Diethelm, V. Singh, J. Van herle, ECS Trans. 68 (2015) 2285-2293.

[5] J. Bao, G. N. Krishnan, P. Jayaweera, J. Perez-Mariano, A. Sanjurjo, J. Power Sources 193 (2009) 607616.

[6] A. Nakajo, P. Tanasini, S. Diethelm, J. Van herle, D. Favrat, J. Electrochem. Soc. 158 (2011) B1102B1118.

[7] L. Kröll, L. G. J. de Haart, I. Vinke, R.-A. Eichel, Phys. Rev. Applied 7 (2017) 044007.

[8] M. Ecker, J. B. Gerschler, J. Vogel, S. Käbitz, F. Hust, P. Dechent, D. U. Sauer, J. Power Sources 215 (2012) 248-257.

[9] J. Schmalstieg, S. Käbitz, M. Ecker, D. U. Sauer, J. Power Sources 257 (2014) 325-334.

[10] M. White, J. B. Bernstein, JPL Puplication 08-5 (2008).

[11] M. S. Khan, S.-B. Lee, R.-H. Song, J.-W. Lee, T.-H. Lim, S.-J. Park, Ceram. Int. 42 (2016) 35-48.

[12] Z. Yang, M. Guo, N. Wang, C. Ma, J. Wang, M. Han, Int. J. Hydrogen Energy 42 (2017) 24948-24959.

[13] H. Yokokawa, H. Tu, B. Iwanschitz, A. Mai, J. Power Sources 182 (2008) 400-412.

[14] L. G. J. de Haart, J. Mougin, O. Posdziech, J. Kiviaho, N. H. Menzler, Fuel Cells 9 (2009) 794-804.

[15] J. W. McPherson, Reliability Physics and Engineering: Time-to-failure modeling, Springer International Publishing Schwitzerland, 2013.

[16] M. Guida, F. Postiglione, G. Pulcini, Reliab. Eng. Syst. Safety. 140 (2015) 88-98. 
[17] DOE, The department of energy hydrogen and fuel cells program plan. https://www.hydrogen.energy.gov/roadmaps_vision.html, 2018 (accessed 22 January 2018)

[18] A. Ploner, A. Hagen, A. Hauch, Fuel Cells 17 (2017) 498-507.

[19] A. Hagen, Y. L. Liu, R. Barfod, P. V. Hendriksen, J. Electrochem. Soc. 155 (2008) B1047-B1052.

[20] A. Hauch, M. Mogensen, A. Hagen, Solid State Ionics 192 (2011) 547.

[21] L. Holzer, B. Iwanschitz, T. Hocker, B. Münch, M. Prestat, D. Wiedenmann, U. Vogt, P. Holtappels, J. Sfeir, A. Mai, T. Graule, J. Power Sources 196 (2011) 1279-1294.

[22] A. Hagen, R. Barfod, P. V. Hendriksen, Y.-L. Liu, S. Ramousse, J. Electrochem. Soc. 153 (2006) A1165-A1171.

[23] M. V. Ananyev, D. I. Bronin, D. A. Osinkin, V. A. Eremin, R. Steinberger-Wilckens, L. G. J. de Haart, J. Mertens, J. Power Sources 286 (2015) 414-426.

[24] K. Thydén, Microstructural degradation of Ni-YSZ anodes for solid oxide fuel cells, Ph.D. dissertation, Technical University of Denmark, 2008.

[25] L. A. Escobar, W. Q. Meeker, Statist. Sci. 21 (2006) 552-577.

[26] S.-J. L. Kang, Sintering: Densification, Grain Growth and Microstructure, Elsevier, 2005.

[27] J. Sehested, J. A. P. Gelten, S. Helveg, Appl. Catal., A 309 (2006) 237-246.

[28] D. S. Peck, 24th IEEE Int. Reliab. Phys. Symp. Proc. 215 (1986) 44-50.

[29] F. Abdeljawad, B. Völker, R. Davis, R. M. McMeeking, M. Haataja, J. Power Sources 250 (2014) 319331.

[30] 15th Annual SECA workshop. https://www.netl.doe.gov/events/conference-proceedings/2014/15thannual-seca-workshop, 2018 (accessed 22 January 2018)

[31] A. Faes, A. Hessler-Wyser, D. Presvytes, C. G. Vayenas, J. Van herle, Fuel Cells 9 (2009) 841-851.

[32] H. Parikh, N. Hilli, M. R. De Guire, A. H. Heuer, Z. Liu, R. Goettler, J. Am. Ceram. Soc. 100 (2017) 1653-1660.

[33] P. Tanasini, M. Cannarozzo, P. Costamagna, A. Faes, J. Van Herle, A. Hessler-Wyser, C. Comninellis, Fuel Cells 9 (2009) 740-752.

[34] X. Mantzouris, N. Zouvelou, D. Skarmoutsos, P. Nikolopoulos, F. Tietz, J. Mater. Sci. 40 (2005) 2471- 
2475.

[35] D. Simwonis, F. Tietz, D. Stoever, Solid State Ionics 132 (2000) 241-251.

[36] S. P. Jiang, J. Mater. Sci. 38 (2003) 3775 - 3782.

[37] D. Kennouche, Y.-c. K. Chen-Wiegart, C. Riscoe, J. Wang, S. A. Barnett, J. Power Sources 307 (2016) 604-612.

[38] M. H. Pihlatie, A. Kaiser, M. Mogensen, M. Chen, Solid State Ionics 189 (2011) 82-90.

[39] C. H. Bartholomew, Appl. Catal., A 107 (1993) 1-57.

[40] A. Hauch, S. D. Ebbesen, S. H. Jensen, M. Mogensen, J. Electrochem. Soc. 155 (2008) B1184-B1193. 